\title{
Effect of new and conventional technological processes on the terroir marker ${ }^{87} \mathrm{Sr} /{ }^{86} \mathrm{Sr}$
}

\author{
Sofia Catarino ${ }^{1,2,3, a}$, Cíntia Moreira ${ }^{3}$, Ayse Kaya ${ }^{1}$, Raúl Bruno de Sousa ${ }^{1}$, António Curvelo-Garcia ${ }^{2}$, Maria de Pinho ${ }^{3}$, \\ and Jorge Ricardo-da-Silva ${ }^{1}$ \\ ${ }^{1}$ LEAF, Instituto Superior de Agronomia, Universidade de Lisboa, Tapada da Ajuda, 1349-017 Lisboa, Portugal \\ ${ }^{2}$ Instituto Nacional de Investigação Agrária e Veterinária, 2565-191 Dois Portos, Portugal \\ ${ }^{3}$ CEFEMA, Instituto Superior Técnico, Universidade de Lisboa, Av. Rovisco Pais, 1, 1049-001 Lisboa, Portugal
}

\begin{abstract}
Aiming to use the strontium isotopic ratio ${ }^{87} \mathrm{Sr} /{ }^{86} \mathrm{Sr}$ for traceability and authentication of wine, it is crucial to understand the impacts of anthropogenic factor and technological processes on this parameter. In this study the effect of two technologies: nanofiltration (NF), applied for wine dealcoholisation (1), and ageing with oak wood staves (2), on ${ }^{87} \mathrm{Sr} /{ }^{86} \mathrm{Sr}$ ratio of wines from Portuguese Designations of Origin (DO), was assessed. Control wines, NF processed wines and wooden aged wines were evaluated for chemical composition, multi-elemental composition and ${ }^{87} \mathrm{Sr} /{ }^{86} \mathrm{Sr}$ ratio by Q-ICP-MS. Regarding NF experiments, high rejections to mineral elements, including heavy metals, were observed. Bearing in mind the several roles played by these elements in wine, this knowledge is of strategic importance in order to guarantee that NF process does not adversely affect product quality. Concerning wood ageing experiment, results indicate the influence of this technological process on metal physical-chemical stability. In the experimental conditions of this study, no significant effect of NF process and wood ageing on ${ }^{87} \mathrm{Sr} /{ }^{86} \mathrm{Sr}$ ratio was observed, suggesting that the application of these technologies in wine production is not a limitative factor for the use of ${ }^{87} \mathrm{Sr} /{ }^{86} \mathrm{Sr}$ ratio as a geographical origin marker.
\end{abstract}

\section{Introduction}

Closely related to the idea that terroir determines the quality and character of wines, many efforts have been made to identify potential markers and develop reliable analytical methods to determine the wine's geographical origin.

The isotopic ratio ${ }^{87} \mathrm{Sr} /{ }^{86} \mathrm{Sr}$ is a well-established tool for dating and tracing the origin of rocks and minerals [1] with special interest for wine traceability. Several studies on its use for wine geographical origin assessment can be found in literature [2-8]. Recently, within a research program regarding strategies for wine fingerprinting, the authors confirmed ${ }^{87} \mathrm{Sr} /{ }^{86} \mathrm{Sr}$ as a viable tool for traceability of Portuguese DO, where soils were developed on different geological formations $[9,10]$.

The use of this parameter as a marker of wine geographical origin is based on the assumption that a relation between soil, plants and wine exists. Therefore, ${ }^{87} \mathrm{Sr} /{ }^{86} \mathrm{Sr}$ ratio should not be significantly modified during wine processing. Aiming to use ${ }^{87} \mathrm{Sr} /{ }^{86} \mathrm{Sr}$ for traceability and authentication of wine, it is mandatory to clarify the impacts of anthropogenic factors and technological processes on this isotopic ratio. This is a current subject of major importance addressed in this study.

$\mathrm{NF}$ is a versatile membrane process, with several applications in wine production where its use is increasing, e.g. for ethanol content modulation but also for reduction of the sugar content in musts, volatile acidity correction

\footnotetext{
${ }^{a}$ Corresponding author: sofiacatarino@isa.ulisboa.pt
}

and to remove excess of ethyl-phenols [11]. NF effects on wine composition have been assessed, namely on alcoholic strength, total acidity and phenolic composition [12,13]. Nevertheless, to the best of our knowledge, its influence on mineral composition and wine ${ }^{87} \mathrm{Sr} /{ }^{86} \mathrm{Sr}$ is not known.

Wood aging is a traditional practice widely used in wine production. Currently, as alternative to wood barrels, in order to improve the traditional process in conditions that sustain the economic viability of this practice, the use of wood pieces in stainless-steel tanks is widespread. In spite of substantial understanding of the organic extractable compounds, little has been published on metal extraction from wood to wine, and no data about its influence on ${ }^{87} \mathrm{Sr} /{ }^{86} \mathrm{Sr}$.

In spite of a few studies suggesting that ${ }^{87} \mathrm{Sr} /{ }^{86} \mathrm{Sr}$ isotopic ratio remains stable after enological processes $[3,5,14,15]$, the literature lacks the information on the NF process and wood ageing influence on ${ }^{87} \mathrm{Sr} /{ }^{86} \mathrm{Sr}$ isotopic ratio. The main aim of this study was to uncover the effect of NF and wood ageing by oak staves on strontium ${ }^{87} \mathrm{Sr} /{ }^{86} \mathrm{Sr}$ isotopic ratio. Furthermore, information on the effect of these technologies on mineral composition of wines was obtained.

\section{Materials and methods}

\subsection{Nanofiltration experiments}

For NF experiments, three white wines (WW) and three red wines (RW) from the Portuguese DO Dão, Óbidos and Palmela were used. White wines, from 2014 vintage, 


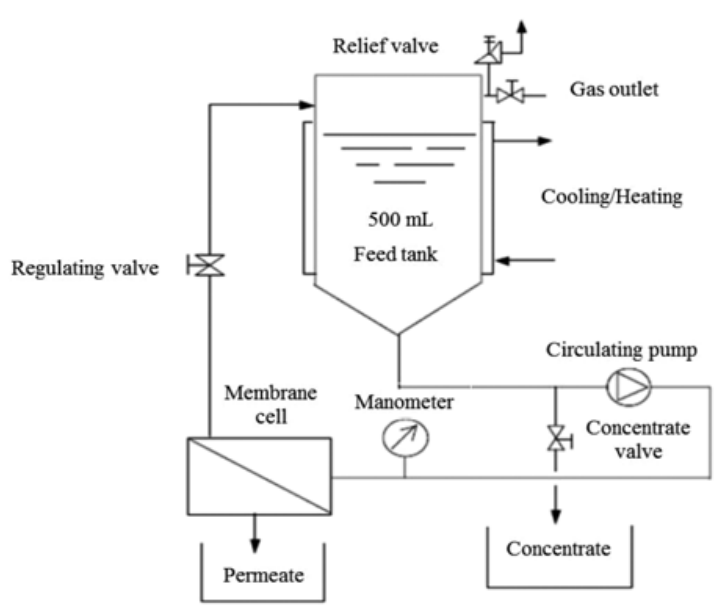

Figure 1. Set up of the nanofiltration unit.

were produced using the following grape varieties (Vitis vinifera L.): Fernão Pires (Óbidos); Verdelho and Viosinho (Palmela); Verdelho (Dão). Red wines, from 2013 vintage, resulted from the following grape varieties (Vitis vinifera L.): Calladoc, Syrah and Alicante Bouchet (Óbidos); Castelão (Palmela); Touriga Nacional (Dão).

NF experiments were carried out at laboratory scale in the unit Celfa P-28 for dealcoholisation of white and red wines (Fig. 1).

Regarding the NF membrane used, a cellulose acetate membrane was laboratory made and characterized, presenting hydraulic permeability of $0.313 \mathrm{~kg} /\left(\mathrm{h} . \mathrm{m}^{2} . \mathrm{bar}\right)$ and rejection coefficients of $90.3 \%$ to $\mathrm{NaCl}, 95.3 \%$ to $\mathrm{Na}_{2} \mathrm{SO}_{4}, 92.8 \%$ to $\mathrm{CaSO}_{4}$ and $90.3 \%$ to glucose. Rejection coefficients (f) to solutes were determined using equation 1 , where $\mathrm{C}_{f}$ and $\mathrm{C}_{p}$ are the concentrations in feed and permeate, respectively:

$$
\mathrm{f}=\left(\mathrm{C}_{\mathrm{f}}-\mathrm{C}_{\mathrm{p}}\right) / \mathrm{C}_{\mathrm{f}}
$$

NF experiments were carried out at a transmembrane pressure of 17 bar and a feed recirculation flow rate of 2.1 L/min. Each NF fraction (initial feed, final feed and permeate) was evaluated through summary analysis and total polysaccharides, total anthocyanins, total phenolic index, multi-elemental composition and ${ }^{87} \mathrm{Sr} /{ }^{86} \mathrm{Sr}$ isotopic ratio.

\subsection{Ageing experiments}

A red wine from Castelão grape variety (Palmela DO), 2014 vintage, was aged in stainless steel vats $(34,000$ L) with wood staves, in triplicate. French oak (Quercus sessiliflora Salisb.) staves, with medium plus toasting level $\left(<200^{\circ} \mathrm{C}\right)$, in dimensions of $91 \mathrm{~cm}$ (length) $\times 6.4 \mathrm{~cm}$ (width) $\times 0.95 \mathrm{~cm}$ (thickness) were used, one oak stave per $40 \mathrm{~L}$ of wine. Micro-oxygenation was applied with the amount of $3 \mathrm{mg} / \mathrm{L}$ per month. Storing temperature of the tanks was $18^{\circ} \mathrm{C}$. The experiment was carried out with one control vat without oak staves.

The wines were sampled after 30, 60 and 90 days of ageing (a total of 16 samples) and evaluated in terms of general analysis, total polysaccharides, total anthocyanins, total phenols index, multi-elemental composition and ${ }^{87} \mathrm{Sr} /{ }^{86} \mathrm{Sr}$ isotopic ratio.

\subsection{Analytical determinations}

\subsubsection{Physical-chemical characterization}

Alcoholic strength, total acidity, volatile acidity, tartaric acid, malic acid, lactic acid, total dry matter, ash, density, $\mathrm{pH}$, total sulphur dioxide, reducing substances, colour intensity and tonality, were determined according to OIV analysis methods [16], in the samples from ageing experiments.

Due to the low sample volume available for analysis, wine NF streams (initial feed, final feed and permeate) were analysed for the before referred analytical parameters by Fourier Transform Infrared (FTIR) technique using a Foss WineScan FT 120 equipment.

Total polysaccharides were assessed through phenolsulfuric method (colorimetric method), after the separation of polysaccharides by ethanol. Total anthocyanins and total phenols index determinations were carried out as described by Somers and Evans [17].

\subsubsection{Multi-elemental analysis}

Thirty-six minor and trace elements were measured by quadrupole inductively coupled plasma mass spectrometry (Q-ICP-MS) semi-quantitative methodology according to the protocol described by Catarino et al. [18].

A Perkin-Elmer SCIEX Elan 9000 Q-ICP-MS apparatus, equipped with a peristaltic sample delivery pump with four channels model Gilson, a Scott-type spray chamber made of Ryton, a crossflow nebulizer, nickel cones and an autosampler Perkin-Elmer AS-93 Plus, protected by a laminar-flow-chamber clean room class 100 was used. The system was controlled by software Elan -6100 Windows NT (Version 2.4).

Major mineral elements $(\mathrm{Na}, \mathrm{K}, \mathrm{Ca}, \mathrm{Fe})$ were determined in wines from ageing experiments by Flame Atomic Absorption Spectrophotometry (FAAS) according to the methods described by OIV [16].

\subsection{3. ${ }^{87} \mathrm{Sr} /{ }^{86} \mathrm{Sr}$ isotopic ratio determination}

Due to isobaric overlap of ${ }^{87} \mathrm{Rb}$ and ${ }^{87} \mathrm{Sr}$, an effective $\mathrm{Rb}$ and $\mathrm{Sr}$ separation is required before ICP-MS analysis, in order to accurate determination of ${ }^{87} \mathrm{Sr} /{ }^{86} \mathrm{Sr}$ isotopic ratios. Wine samples treatment is composed by three steps: digestion by High Pressure Microwave (HPMW), chromatographic separation of $\mathrm{Sr}$ and $\mathrm{Rb}$ and filtration of Sr chromatographic fraction.

${ }^{87} \mathrm{Sr} /{ }^{86} \mathrm{Sr}$ isotopic ratio determination by Q-ICP-MS was carried out according to protocol described by the authors [9], using the Q-ICP-MS equipment previously described. Analytical calibration and stability control in ${ }^{87} \mathrm{Sr} /{ }^{86} \mathrm{Sr}$ isotopic ratio analysis were made with $\mathrm{SrCO}_{3}$ $(50 \mu \mathrm{g} / \mathrm{L})$, prepared from certified reference material NIST SRM 987 (SrCO3).

\subsection{Statistical analysis}

Analysis of variance (ANOVA) was carried out to assess the effect of nanofiltration and wooden ageing on the ${ }^{87} \mathrm{Sr} /{ }^{86} \mathrm{Sr}$ isotopic ratio of wines. Fisher's least significant difference (LSD, significance level of 0.05) test was applied to compare the different averages. All calculations were carried out using Statistica version 7 (StatSoft Inc., Tulsa, USA). 
Table 1. Physical-chemical characteristics of wines nanofiltration streams (I.F. - initial feed; F.F. - final feed; P. - permeate).

\begin{tabular}{lllllll}
\hline & \multicolumn{3}{c}{ WW Dão DO } & \multicolumn{3}{c}{ RW Óbidos DO } \\
\cline { 2 - 7 } & I.F. & F.F. & P. & I.F. & F.F. & P. \\
\hline Alcoholic strength at $20^{\circ} \mathrm{C}(\% \mathrm{v} / \mathrm{v})$ & 12.6 & 12.5 & 11.7 & 11.9 & 11.9 & 11.3 \\
Total acidity (g/L tartaric acid) & 5.60 & 4.86 & 0.74 & 4.71 & 4.98 & 1.31 \\
Volatile acidity (g/L acetic acid) & 0.29 & 0.28 & 0.18 & 0.56 & 0.56 & 0.44 \\
Tartaric acid (g/L) & 1.51 & 1.17 & nd & 0.87 & 0.83 & $\mathrm{nd}$ \\
Malic acid (g/L) & 1.90 & 1.56 & nd & - & - & - \\
Lactic acid (g/L) & 0.08 & 0.16 & 0.16 & 1.72 & 1.89 & 0.44 \\
Total dry matter (g/L) & 20.7 & 17.9 & 1.5 & 27.5 & 30.7 & 2.6 \\
Ash $(\mathrm{g} / \mathrm{L})$ & 2.17 & 1.92 & 0.43 & 3.32 & 3.60 & 0.43 \\
Density at 20 ${ }^{\circ} \mathrm{C}(\mathrm{g} / \mathrm{mL})$ & 0.9897 & 0.9887 & 0.9832 & 0.9931 & 0.9943 & 0.9841 \\
pH & 3.22 & 3.22 & 3.13 & 3.59 & 3.63 & 3.14 \\
Total sulfur dioxide (mg/L) & 95 & 89 & 56 & 53 & 57 & 67 \\
Reducing substances (g/L) & 3.24 & 2.57 & 0.62 & 3.12 & 3.60 & 0.26 \\
Total polysaccharides (mg/L) & 416 & 583 & $\mathrm{nq}$ & 717 & 977 & $\mathrm{nq}$ \\
Color intensity (u.a) & - & - & - & 13.810 & 14.945 & 0.012 \\
Tonality & - & - & - & 0.697 & 0.760 & 21.000 \\
Total anthocyanins (mg/L) & - & - & - & 229 & 296 & 13 \\
Total phenols index (u.a.) & 6 & 7 & 1 & 53 & 62 & 1 \\
\hline
\end{tabular}

nd - not detected; nq - not quantified.

\section{Results and discussion}

\subsection{Nanofiltration of wines}

\subsubsection{Physical-chemical characteristics of NF streams}

Physical-chemical characteristics of NF streams (initial feed, final feed and permeate) from a white wine and a red wine (WW Dão DO and RW Óbidos DO, as examples) are displayed in Table 1.

As expected, ethanol was preferentially permeated by membrane. Rejections to tartaric, malic, lactic and acetic wines were in general high. Regarding polysaccharides, a complete retention was verified. Results relatively to total phenols index and anthocyanins indicate a high rejection to phenolic compounds. It was observed the increase of colour intensity and tonality. For the majority of chemical compounds concentrations in final feed increased with NF treatment due to water and ethanol removal.

In general, rejections higher than $90 \%$ to mineral elements, including heavy metals, were observed. Concentrations in final feed were slightly higher than concentrations in initial feed, due to water and ethanol removal. Bearing in mind the several roles played by these elements in wine, this knowledge is of strategic importance in order to guarantee that NF process does not adversely affect product quality.

Rejection to $\mathrm{Sr}$ was mostly higher than 95\%, suggesting that NF does not change the ${ }^{87} \mathrm{Sr} /{ }^{86} \mathrm{Sr}$ isotopic ratio. Table 2 shows the ${ }^{87} \mathrm{Sr} /{ }^{86} \mathrm{Sr}$ isotopic ratios of wine NF fractions. Strontium isotopic ratio in final feed was not significantly different from ${ }^{87} \mathrm{Sr} /{ }^{86} \mathrm{Sr}$ initial feed, revealing that no preferential permeation of any strontium isotopes occurred.

As expected, ${ }^{87} \mathrm{Sr} /{ }^{86} \mathrm{Sr}$ values were higher for DO Dão, characterized by granitic soils (older). Palmela and Óbidos DO, mainly characterized by sandy and clay soils, showed lower ${ }^{87} \mathrm{Sr} /{ }^{86} \mathrm{Sr}$ ratios. These results are in accordance with previous research of the authors involving soils from these DO [9]. The highest ${ }^{87} \mathrm{Sr} /{ }^{86} \mathrm{Sr}$ values were found in soils from Dão, pointing out a relation between soils and wines.
Table 2. ${ }^{87} \mathrm{Sr} /{ }^{86} \mathrm{Sr}$ isotopic ratio in wine NF streams (I.F. - Initial feed; F.F. - final feed; P. - Permeate).

\begin{tabular}{ll}
\hline Wine NF stream & ${ }^{87} \mathbf{S r}{ }^{86} \mathbf{S r}$ \\
\hline Palmela WW I.F. & $0.7075 \pm 0.0007 \mathrm{a}, \mathrm{b}, \mathrm{c}$ \\
Palmela WW F.F. & $0.7075 \pm 0.0007 \mathrm{a}, \mathrm{b}, \mathrm{c}$ \\
Palmela RW I.F. & $0.709 \pm 0.000 \mathrm{c}, \mathrm{d}$ \\
Palmela RW F.F. & $0.7075 \pm 0.0007 \mathrm{a}, \mathrm{b}, \mathrm{c}$ \\
Óbidos WW I.F. & $0.7080 \pm 0.0008 \mathrm{a}, \mathrm{b}, \mathrm{c}, \mathrm{d}$ \\
Óbidos WW F.F. & $0.709 \pm 0.001 \mathrm{~b}, \mathrm{c}, \mathrm{d}$ \\
Óbidos RW I.F. & $0.709 \pm 0.000 \mathrm{c}, \mathrm{d}$ \\
Óbidos RW F.F. & $0.7095 \pm 0.0007 \mathrm{~d}$ \\
Dão WW I.F. & $0.713 \pm 0.000 \mathrm{e}$ \\
Dão WW F.F. & $0.714 \pm 0.000 \mathrm{e}, \mathrm{f}$ \\
Dão RW I.F. & $0.715 \pm 0.001 \mathrm{f}$ \\
Dão RW F.F. & $0.714 \pm 0.001 \mathrm{e}, \mathrm{f}$ \\
\hline
\end{tabular}

Results are based on average values of two independent replicates and respective standard deviation. Means followed by the same letter are not significantly different at the 0.05 level of significance.

\subsection{Wood ageing}

\subsubsection{Mineral composition and ${ }^{87} \mathrm{Sr} /{ }^{86} \mathrm{Sr}$ isotopic ratio}

Table 3 displays the concentrations of some elements in Control and Wood wines at the end of the experiment (90 days). Wine treated with oak wood staves showed significantly different concentrations for the elements $\mathrm{Na}$, $\mathrm{V}, \mathrm{Co}, \mathrm{Ni}, \mathrm{Sr}, \mathrm{Cs}$ and $\mathrm{Pb}$, compared to the Control. Particular attention must be paid to the differences in $\mathrm{V}, \mathrm{Co}$ and $\mathrm{Ni}$ concentrations between Control and Wood wines. Higher concentrations of these elements in Wood in comparison with Control are most probably explained by its more intense precipitation through time in the wine without wood staves. This hypothesis is supported by the concentrations of $\mathrm{V}, \mathrm{Co}$ and $\mathrm{Ni}$ in Control wine at the beginning of the ageing experiment (results not shown). For the rest of the elements, despite no significant effect of wood treatment was observed, metals concentrations tend to be higher in the wine treated with oak wood staves. 
Table 3. Mineral composition of the wine treated with oak wood staves and of the control wine at the end of the experiment, 90 days (Results are given in $\mu \mathrm{g} / \mathrm{L}$, except for $\mathrm{Na}, \mathrm{Mg}, \mathrm{Al}, \mathrm{K}$, $\mathrm{Ca}, \mathrm{Mn}, \mathrm{Fe}$ and $\mathrm{Zn}$, which are expressed as $\mathrm{mg} / \mathrm{L})^{\mathrm{a}}$.

\begin{tabular}{llll}
\hline & Treatment effect $^{\mathbf{b}}$ & Control & Wood \\
\hline $\mathbf{L i}$ & n.s. & $11.3 \pm 0.3$ & $12.2 \pm 0.2$ \\
$\mathbf{N a}$ & $* * *$ & $28.38 \pm 0.03 \mathrm{a}$ & $30.37 \pm 0.04 \mathrm{~b}$ \\
$\mathbf{M g}$ & n.s. & $56 \pm 2$ & $59.7 \pm 0.5$ \\
$\mathbf{A l}$ & n.s. & $171 \pm 7$ & $180.3 \pm 0.5$ \\
$\mathbf{K}$ & n.s. & $993 \pm 91$ & $1069 \pm 3$ \\
$\mathbf{C a}$ & n.s. & $55 \pm 1$ & $53.3 \pm 0.6$ \\
$\mathbf{V}$ & $* * *$ & $0.45 \pm 0.02 \mathrm{a}$ & $0.970 \pm 0.004 \mathrm{~b}$ \\
$\mathbf{M n}$ & n.s & $0.76 \pm 0.04$ & $0.83 \pm 0.03$ \\
$\mathbf{F e}$ & n.s. & $2.42 \pm 0.03$ & $2.7 \pm 0.1$ \\
$\mathbf{C o}$ & $* * *$ & $1.9 \pm 0.1 \mathrm{a}$ & $2.80 \pm 0.03 \mathrm{~b}$ \\
$\mathbf{N i}$ & $* * *$ & $12.6 \pm 0.5 \mathrm{a}$ & $52 \pm 2 \mathrm{~b}$ \\
$\mathbf{C u}$ & n.s. & $21.9 \pm 0.9$ & $26 \pm 2$ \\
$\mathbf{Z n}$ & n.s. & $0.3 \pm 0.1$ & $0.319 \pm 0.009$ \\
$\mathbf{G a}$ & n.s. & $2.6 \pm 0.2$ & $2.8 \pm 0.6$ \\
$\mathbf{A s}$ & n.s. & $0.9 \pm 0.1$ & $1.04 \pm 0.04$ \\
$\mathbf{R b}$ & n.s. & $1175 \pm 59$ & $1249 \pm 17$ \\
$\mathbf{S r}$ & $*$ & $237 \pm 9 \mathrm{a}$ & $265 \pm 7 \mathrm{~b}$ \\
$\mathbf{C s}$ & $*$ & $4.6 \pm 0.2 \mathrm{a}$ & $5.1 \pm 0.1 \mathrm{~b}$ \\
$\mathbf{T l}$ & n.s. & $0.293 \pm 0.009$ & $0.33 \pm 0.01$ \\
$\mathbf{P b}$ & $*$ & $3.8 \pm 0.2 \mathrm{a}$ & $4.5 \pm 0.2 \mathrm{~b}$ \\
\hline
\end{tabular}

${ }^{a}$ Control: the results are based on average values of analysis duplicates. Wood: the results are based on average values of experimental triplicates and analyses duplicates. ${ }^{\mathrm{b}}$ Means followed by the same letter in a line are not significantly different at the $0.05^{*}$ or $0.001^{* * *}$ level of significance; n.s. $=$ without significant difference. ${ }^{\mathrm{b}}$ Control: the results are based on average values of analysis duplicates. Wood: the results are based on average values of experimental triplicates and analyses duplicates.

Concerning ${ }^{87} \mathrm{Sr} /{ }^{86} \mathrm{Sr}$ isotopic ratio, the values were of $0.710 \pm 0.001$ and $0.709 \pm 0.001$ in Control and Wood, respectively. Under these experimental conditions, the ${ }^{87} \mathrm{Sr} /{ }^{86} \mathrm{Sr}$ isotopic ratio of wine was not significantly affected by the wood treatment suggesting that wood ageing does not preclude the use of this parameter as a marker of geographical origin.

Additional results and comprehensive discussion concerning this research are being prepared for publication.

The authors acknowledge the Companhia Agrícola do Sanguinhal Lda, José Maria da Fonseca Vinhos S.A. and Sogrape Vinhos S.A. for providing their facilities regarding the study development; the staff of Membranes Laboratory (Instituto Superior Técnico), Enology Laboratory (Instituto Superior de Agronomia) and Mineral Analysis Laboratory, namely Otília Cerveira (INIAV, Dois Portos) for technical support. This work was supported by the Portuguese National Funding Agency for Science and Technology through the grant SFRH/BPD/93535/2013 and through the research centres LEAF (UID/AGR/04129/2013) and CEFEMA (UID/CTM/04540/2013).

\section{References}

[1] R.C. Capo, B.W. Stewart, O.A. Chadwick, Geoderma 82, 197-225 (1998)

[2] P. Horn, P. Schaaf, B. Holbach, S. Hölzl, H. Eschnauer, Z. Lebensm. Unters. Forsch. 196, 407-409 (1993)

[3] P. Horn, S. Hölzl, W. Todt, D. Matthies, Isot. Environ. Healt. Stud. 33 (1-2), 31-42 (1997)

[4] C.M. Almeida, M.T.S.D. Vasconcelos, J. Anal. At. Spectrom. 16, 607-611 (2001)

[5] C.M.R. Almeida, M.T.S.D. Vasconcelos, Food Chem. 85, 7-12 (2004)

[6] S. Marchionni, E. Braschi, S. Tommasini, A. Bollati, F. Cifelli, N. Mulinacci, M. Mattei, S. Conticelli. S., J. Agric. Food Chem. 61 (28), 6822-6831 (2013)

[7] M. Mercurio, E. Grilli, P. Odierna, V. Morra, T. Prohaska, E. Coppola, C. Grifa, A. Buondonno, A Langella, Geoderma 230-231, 64-78 (2014)

[8] C. Durante, C. Baschieri, L. Bertacchini, D. Bertelli, M. Cocchi, A. Marchetti, D. Manzini, G. Papotti, S. Sighinolfi, Food Chem. 173, 557-563 (2015)

[9] P. Martins, M. Madeira, F. Monteiro, R. Bruno de Sousa, A.S. Curvelo-Garcia, S. Catarino, J. Int. Sci. Vigne Vin, 48 (1), 21-29 (2014)

[10] S. Catarino, R. Bruno de Sousa, A.S. Curvelo-Garcia, Origem geográfica. In: A.S. Curvelo Garcia A.S. \& P. Barros (eds). Química enológica - métodos analíticos. Avanços recentes no controlo da qualidade de vinhos e de outros produtos vitivinícolas, 513-538. Publindústria, Porto (2015)

[11] OIV. International Code of Oenological Practices. Organisation Internationale de la Vigne et du Vin, Paris (2015)

[12] M. Catarino, A. Mendes, Innov. Food Sci. Emerg. 12 (3), 330-337 (2011)

[13] F. Gonçalves, R. Ribeiro, L. Neves, T. Lemperle, M. Lança, J. Ricardo da Silva, O. Laureano. In: P.-L. Teissedre (coord.). Proc. $1^{\text {st }}$ International Symposium of Oenoviti International Network, 64-67. Bordeaux (2013)

[14] V. Victor, S. Ross, P. Karine, P. André, H. JeanFrançois, W. David, Procedia Earth and Planetary Science 13, 252-255 (2015)

[15] S. Marchionni, A. Buccianti, A. Bollati, E. Braschi, F. Cifelli, P. Molin, M. Parotto, M. Mattei, S. Tommasini, S. Conticelli, Food Chem. 190, 777-785 (2016)

[16] OIV. Compendium of International Methods of Wine and Must Analysis I/II, Organisation Internationale de la Vigne et du Vin: Paris, France (2014)

[17] T.C. Somers, M.E. Evans, J. Sci. Food Agr., 28, 279-287 (1977)

[18] S. Catarino, A.S. Curvelo-Garcia, R. Bruno de Sousa, Talanta, 70, 1073-1080 (2006) 